\title{
Sobrecarga no cuidar e suas repercussões nos cuidadores de pacientes em fim de vida: revisão sistemática da literatura
}

\author{
Burden of caregiving and its repercussions on caregivers \\ of end-of-life patients: a systematic review of the literature
}

Mayra Delalibera ${ }^{1}$

Joana Presa ${ }^{2}$

António Barbosa ${ }^{2}$

Isabel Leal ${ }^{1}$
${ }^{1}$ Instituto Superior de Psicologia Aplicada. R. Jardim do Tabaco, 34. 1149-041 Lisboa Portugal. mayrarmani@yahoo.com.br ${ }^{2}$ Unidade de Medicina Paliativa, Centro Hospitalar Lisboa Norte.

\begin{abstract}
Caring for a family member with an advanced and/or terminal illness can be a great emotional, physical and financial burden that has an impact on the quality of life of the caregivers. The scope of this study was to conduct a systematic review of the literature on the burden of caregiving, related factors and the consequences for family caregivers of advanced stage cancer patients or patients in end-of-life or palliative care. A search for scientific papers published in the EBSCO, Web of Knowledge and BIREME databases was conducted since records on this topic began in the databases through March 2014. Of the 582 articles found, only 27 were selected. The majority of the articles found that family caregivers were overburdened. Some studies found that the caregiving burden was associated with characteristics of the patients and their illnesses while, in other studies, it was associated with poor health of the caregiver, greater psychopathological symptoms (anxiety, depression, emotional distress) and with the development of complications in the grieving process. However, hope, social support, the ability of the caregiver to attribute meaning to the experience of caring and feeling comfortable with the tasks of caring were associated with lower levels of burden.
\end{abstract}

Key words Caregiver burden, Family caregivers, End-of-life, Palliative care
Resumo Cuidar de um familiar com doença avançada elou em fim de vida pode representar uma grande sobrecarga emocional, física e financeira que afeta a qualidade de vida dos cuidadores. O presente estudo teve como objetivo realizar uma revisão sistemática da literatura sobre a sobrecarga no cuidar, os fatores relacionados e suas consequências nos cuidadores de pacientes com câncer avançado em fim de vida ou em cuidados paliativos. Foi realizada uma busca de artigos científicos publicados nas bases de dados EBSCO, Web of Knowledge e Bireme, desde os primeiros registros nas respectivas bases de dados sobre o tema até março de 2014. Dos 582 artigos encontrados, apenas 27 foram selecionados. A maioria dos artigos afirma que os cuidadores familiares estão sobrecarregados. Em alguns estudos, a sobrecarga no cuidar aparece associada a características do paciente e da sua doença; em outros, a um pior estado de saúde do cuidador, a uma maior sintomatologia psicopatológica (ansiedade, depressão, distress emocional) e também ao desenvolvimento de complicações no luto. Porém, a esperança, o apoio social, a capacidade do cuidador de atribuir um significado à experiência de cuidar e se sentir confortável com as tarefas de cuidar foram associados a menores niveis de sobrecarga.

Palavras-chave Sobrecarga do cuidador, Cuidadores familiares, Fim de vida, Cuidados paliativos 


\section{Introdução}

Com o aumento da expectativa de vida e o desenvolvimento de meios cada vez mais eficientes para tratar as doenças, as pessoas hoje sobrevivem muito mais tempo e o papel do cuidador se tornou fundamental. Porém, os cuidadores recebem pouca formação ou preparação para cuidar e são envolvidos em muitas atividades para a manutenção do bem-estar do seu familiar, como: gestão e administração de medicamentos, alimentação, cuidados físicos, transporte e administração das tarefas domésticas ${ }^{1,2}$.

A experiência de cuidar de um familiar doente pode representar uma grande sobrecarga emocional, física e financeira, que afeta a qualidade de vida dos cuidadores, uma vez que cuidar de um familiar exige disponibilidade, tempo e dedicação. Cuidar de um paciente com doença crônica ou avançada em casa pode gerar uma sobrecarga considerável nos cuidadores familiares, que podem vir a adoecer, justamente devido ao fato de lidarem diretamente com a maior parte das tarefas na assistência ao paciente em casa, recaindo sobre eles os encargos inerentes do cuidar ${ }^{3-6}$.

Cuidadores familiares desempenham um papel fundamental na manutenção da vida dos indivíduos doentes que necessitam de cuidados. No entanto, estudos relatam que, inerentes à prestação de cuidados, estes cuidadores poderão apresentar ansiedade e depressão ${ }^{7,8}$, estresse e tensão ${ }^{9}$, privação de sono ${ }^{10}$, redução da qualidade de vida $^{11,12}$, sentimento de impotência, desamparo $^{13}$, dificuldades financeiras ${ }^{7}$ decorrentes de possíveis alterações no emprego e gastos médicos. Os cuidadores também ficam mais isolados socialmente e apresentam dificuldades para gerir o trabalho fora de casa e os cuidados com o familiar doente ${ }^{5}$. Em particular, tem-se detectado que os cuidadores de pacientes com câncer terminal experimentam um agravamento geral na saúde física, qualidade de vida ${ }^{1}$ e distress emocional relacionado com a prestação de cuidados ${ }^{9,14}$.

A sobrecarga do cuidador aparece muito frequentemente associada a estados de fadiga física e mental, stress, depressão, ansiedade, falta de apoio social e pior qualidade de vida dos cuidadores $^{15-17}$. A sobrecarga pode estar associada também a características do paciente como o distress psicológico, qualidade de vida e falta de controle dos sintomas do paciente ${ }^{18}$.

Para além das consequências negativas já descritas, que podem estar associadas a sobrecarga no cuidar, alguns estudos têm demonstrado que o impacto da prestação de cuidados é considerá- vel e pode se estender para o período de luto ${ }^{19,20}$, e a sobrecarga do cuidador tem sido um dos fatores de risco identificados na literatura para o desenvolvimento de um luto complicado ${ }^{19,21}$. Portanto, é importante identificar e dedicar maior atenção a esta população mais vulnerável.

Estudos têm demonstrado que ter acesso a recursos sociais e psicológicos são fundamentais para o sucesso no papel de cuidador ${ }^{22}$, assim como o apoio de outras pessoas ${ }^{23}$. Contudo, apesar dos cuidadores estarem sobrecarregados com o cuidar, alguns estudos identificaram consequências positivas na prestação de cuidados, como: a possibilidade de demonstrar amor, satisfação e sentimentos de realização, o reconhecimento de que cuidar do familiar faz diferença ${ }^{14,24,25}$, a sensação de ter participado de uma experiência gratificante e / ou significativa, fortalecimento das relações $^{26}$ e crescimento pessoal ${ }^{27}$.

Portanto, o objetivo deste estudo foi realizar uma revisão sistemática da literatura sobre a sobrecarga no cuidar, os fatores relacionados e suas consequências nos cuidadores familiares de pacientes com câncer avançado, em fim de vida e/ ou em cuidados paliativos, no sentido de sistematizar e organizar o que há de mais significativo na produção científica em torno da sobrecarga do cuidador.

\section{Metodologia}

Foi realizada uma busca de artigos científicos, publicados em revistas científicas nas bases de dados EBSCO (PsycInfo, PsycArticles, Psychology and Behaviral Sciences Collection, Academic Search Complete), Web of Knolwledge (Web of Science e MEDLINE) e Bireme (Lilacs, IBECS, MEDLINE, Biblioteca Cochrane, SciELO), utilizando a combinação dos seguintes descritores: burden, palliative care, terminally ill, end of life e caregiver. Na Bireme também foram procurados os mesmos termos em português (sobrecarga, cuidados paliativos, fim de vida e cuidadores). Foram pesquisados artigos em inglês, português e espanhol desde que existem registros nas respectivas bases de dados sobre o tema até março de 2014.

Em relação à amostra foram incluídos apenas estudos em que a população era constituída por cuidadores familiares de pacientes oncológicos e/ ou pacientes acompanhados em cuidados paliativos. Foram excluídos artigos teóricos, de comentário ou opinião, dissertações de mestrado, doutorado, comunicações em congressos e estudos 
nos quais os pacientes eram doentes pediátricos (crianças ou adolescentes), devido à especificidade dessa população.

A seleção inicial dos artigos, por meio da leitura do título e resumo, e a exclusão dos duplicados foi realizada pela autora principal (MD) respeitando os critérios de inclusão e exclusão pré-determinados. A leitura completa dos artigos selecionados, e a segunda análise dos estudos foi realizada por dois investigadores independentes (MD e JP), e as dúvidas ou divergências foram discutidas até chegar a um consenso entre os investigadores.

Em relação à qualidade dos estudos, todos os artigos recolheram amostras por conveniência, utilizaram instrumentos fiáveis e validados para avaliar as variáveis selecionadas e análises estatísticas apropriadas.

\section{Resultados}

Foram encontrados 582 artigos relacionados com o tema, dos quais 204 eram repetidos e 316 foram excluídos na primeira avaliação, por não estarem relacionados com a questão de investigação. Não foi possível ter acesso ao texto completo de sete artigos, e 62 foram selecionados para a leitura completa do estudo. Após a segunda análise, constatou-se que 27 artigos cumpriam todos os critérios de inclusão (Figura 1).

Os motivos para a exclusão dos 35 estudos após a leitura completa dos mesmos foram: oito artigos não eram estudos empíricos, eram apenas atualizações ou revisões da literatura que mencionavam a sobrecarga no cuidar; em sete artigos os participantes não cumpriam os critérios de inclusão (familiares de pacientes com doenças neurológicas, doenças crônicas ou não especificadas); três artigos avaliavam a sobrecarga do paciente em fim de vida e não do cuidador; oito artigos ou eram protocolos de programas de intervenção com os cuidadores familiares ou validações de escalas para avaliar a sobrecarga no cuidar, mas que não apresentavam resultados efetivos sobre a sobrecarga do cuidador e dois estudos estavam mais relacionados à avaliação de serviços (Figura 1).

Os artigos selecionados estão mais detalhadamente descritos no Quadro 1. Foram realizados em 13 países diferentes, sendo os Estados Unidos (seis) e o Canadá (cinco) os países com mais publicações, seguidos da Inglaterra (três), Coreia, Itália e Taiwan (dois artigos cada país). Os estudos foram publicados entre 1997 e 2014, com maior concentração em 2013 (seis publicações). Apenas dois artigos foram publicados em espanhol, os demais foram escritos em inglês.

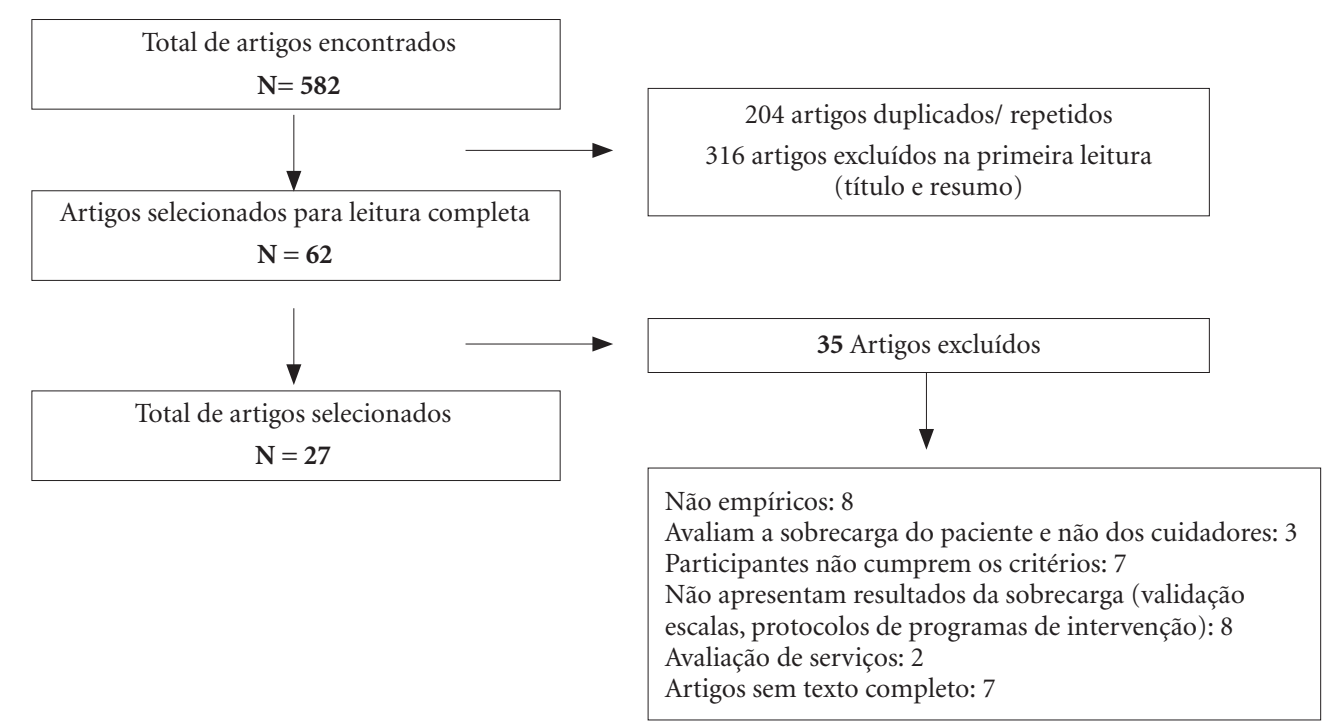

Figura 1. Seleção dos artigos incluídos na revisão. 
Quadro 1. Artigos selecionados para avaliação

\begin{tabular}{|c|c|c|c|c|c|}
\hline $\begin{array}{c}\text { Autor/ano } \\
\text { País }\end{array}$ & Objetivo & $\begin{array}{c}\text { Desenho } \\
\text { estudo }\end{array}$ & População & $\begin{array}{c}\text { Instrumentos } \\
\text { utilizados }\end{array}$ & $\begin{array}{c}\text { Resumo } \\
\text { dos resultados }\end{array}$ \\
\hline $\begin{array}{l}\text { Beery } \\
\text { et al. } \\
(1997)^{28} \\
\text { EUA }\end{array}$ & $\begin{array}{l}\text { Examinar os efeitos } \\
\text { das alterações no papel } \\
\text { funcional, tarefas de } \\
\text { cuidado, sobrecarga do } \\
\text { cuidador, depressão e } \\
\text { luto traumático. }\end{array}$ & $\begin{array}{l}\text { Quantitativo, } \\
\text { longitudinal, } \\
4 \text { avaliações, } \\
\text { do período } \\
\text { de doença } \\
\text { até } 13 \text { meses } \\
\text { após óbito } \\
\text { do paciente }\end{array}$ & $\begin{array}{l}60 \text { cônjuges } \\
\text { de pacientes } \\
\text { terminais, com } \\
50 \text { anos ou mais }\end{array}$ & $\begin{array}{l}\text { - Hamilton } \\
\text { Depression Rating } \\
\text { Scale, } \\
\text {-ITG } \\
\text { - CDQ } \\
\text { - Caregiver's } \\
\text { Sentiments scale }\end{array}$ & $\begin{array}{l}\text { - o nível de sobrecarga do } \\
\text { cuidador foi positivo e } \\
\text { significativamente associado } \\
\text { com o nível de depressão e luto } \\
\text { traumático do entrevistado; } \\
\text { - as mudanças no papel funcional, } \\
\text { especificamente a restrição das } \\
\text { atividades esportivas e recreativas, } \\
\text { foram associadas com o nível de } \\
\text { depressão, mas não com o nível } \\
\text { de luto traumático do cuidador. }\end{array}$ \\
\hline $\begin{array}{l}\text { Braun } \\
\text { et al. } \\
(2007)^{29} \\
\text { Canadá }\end{array}$ & $\begin{array}{l}\text { Avaliar o distress } \\
\text { psicológico de } \\
\text { pacientes com câncer } \\
\text { avançado e seus } \\
\text { cônjuges cuidadores, } \\
\text { e a influência da } \\
\text { sobrecarga, vinculação } \\
\text { e satisfação marital } \\
\text { nos cuidadores } \\
\text { deprimidos. }\end{array}$ & $\begin{array}{l}\text { Quantitativo, } \\
\text { transversal }\end{array}$ & $\begin{array}{l}101 \text { pacientes } \\
\text { com câncer } \\
\text { de pulmão } \\
\text { avançado e } \\
\text { seus cônjuges } \\
\text { cuidadores }\end{array}$ & $\begin{array}{l}\text { - BDI-II (Beck } \\
\text { Depression Inventory) } \\
\text { - Caregiving Burden } \\
\text { Scale, } \\
\text { - Experiences in Close } \\
\text { Relationships Scale } \\
\text { - ENRICH Marital } \\
\text { Satisfaction Scale. }\end{array}$ & $\begin{array}{l}\text { - } 38,9 \% \text { dos cuidadores e } 23 \% \\
\text { dos pacientes relataram sintomas } \\
\text { significativos de depressão; } \\
\text { - cuidadores apresentaram } \\
\text { níveis moderados de sobrecarga } \\
\text { no cuidar e baixa a moderada } \\
\text { dificuldade percebida na } \\
\text { prestação de cuidados aos } \\
\text { pacientes; } \\
\text { - Sobrecarga subjetiva do } \\
\text { cuidador, estilo de vinculação } \\
\text { ansioso e evitante e insatisfação } \\
\text { marital foram preditores } \\
\text { significativos para a depressão do } \\
\text { cônjuge cuidador. }\end{array}$ \\
\hline $\begin{array}{l}\text { Brazil } \\
\text { et al. } \\
(2003)^{30} \\
\text { Canadá }\end{array}$ & $\begin{array}{l}\text { Documentar os } \\
\text { padrões de cuidados } \\
\text { formais e informais } \\
\text { prestados aos } \\
\text { pacientes terminais } \\
\text { e avaliar o impacto } \\
\text { que o cuidar tem nos } \\
\text { membros da família. }\end{array}$ & $\begin{array}{l}\text { Quantitativo, } \\
\text { transversal }\end{array}$ & $\begin{array}{l}151 \text { cuidadores } \\
\text { familiares } \\
\text { de pacientes } \\
\text { em cuidados } \\
\text { paliativos }\end{array}$ & $\begin{array}{l}\text { - CRA (Caregiver } \\
\text { Reaction Assessment) } \\
\text { - Questionário criado } \\
\text { pelos autores }\end{array}$ & $\begin{array}{l}\text { - 41\% dos cuidadores relataram } \\
\text { que prestavam cuidados ao } \\
\text { paciente há mais de um ano; } \\
\text { - 37,7\% dos cuidadores relataram } \\
\text { precisar de mais assistência nos } \\
\text { cuidados ao paciente; } \\
\text {-os cuidadores familiares } \\
\text { que prestavam mais ajuda } \\
\text { nas atividades da vida diária } \\
\text { apresentaram maior risco de } \\
\text { elevada sobrecarga no cuidar; } \\
\text { - pior estado de saúde foi relatado } \\
\text { pelos cuidadores com maior nível } \\
\text { de sobrecarga. }\end{array}$ \\
\hline $\begin{array}{l}\text { Brazil } \\
\text { et al. } \\
(2013)^{31} \\
\text { Canadá }\end{array}$ & $\begin{array}{l}\text { Comparar a } \\
\text { experiência dos } \\
\text { cuidadores familiares } \\
\text { rurais com os } \\
\text { cuidadores familiares } \\
\text { urbanos de pacientes } \\
\text { em fim de vida. }\end{array}$ & $\begin{array}{l}\text { Quantitativo, } \\
\text { Transversal }\end{array}$ & $\begin{array}{l}100 \text { cuidadores } \\
\text { informais }\end{array}$ & $\begin{array}{l}\text { - CBS-EOLC } \\
\text { (Caregiver's Burden } \\
\text { Scale in End-of-Life } \\
\text { Care) } \\
\text { - MSPSS }\end{array}$ & $\begin{array}{l}\text { - cuidadores rurais e urbanos } \\
\text { apresentaram status funcional } \\
\text { semelhante; } \\
\text {-não houve diferenças entre os } \\
\text { cuidadores com } \\
\text { relação à sobrecarga e ambos } \\
\text { cuidadores rurais e urbanos } \\
\text { relatados baixos níveis de } \\
\text { sobrecarga; } \\
\text { - os dois grupos apresentaram } \\
\text { igualmente elevados níveis de } \\
\text { apoio social. }\end{array}$ \\
\hline
\end{tabular}




\begin{tabular}{|c|c|c|c|c|c|}
\hline \multicolumn{6}{|c|}{ Quadro 1. continuação } \\
\hline $\begin{array}{c}\text { Autor/ano } \\
\text { País }\end{array}$ & Objetivo & $\begin{array}{l}\text { Desenho } \\
\text { estudo }\end{array}$ & População & $\begin{array}{c}\text { Instrumentos } \\
\text { utilizados }\end{array}$ & $\begin{array}{c}\text { Resumo } \\
\text { dos resultados }\end{array}$ \\
\hline $\begin{array}{l}\text { Buss et al. } \\
(2007)^{32} \\
\text { EUA }\end{array}$ & $\begin{array}{l}\text { Verificar a relação } \\
\text { entre a percepção } \\
\text { de delírio nos } \\
\text { pacientes por parte } \\
\text { dos cuidadores e a } \\
\text { taxa de perturbações } \\
\text { psiquiátricas dos } \\
\text { cuidadores. }\end{array}$ & $\begin{array}{l}\text { Quantitativo, } \\
\text { transversal }\end{array}$ & $\begin{array}{l}200 \text { cuidadores } \\
\text { de pacientes } \\
\text { com doença } \\
\text { oncológica } \\
\text { avançada }\end{array}$ & $\begin{array}{l}\text { - SCARED (Stressful } \\
\text { Caregiving Response } \\
\text { to Experiences of } \\
\text { Dying) } \\
\text { - SPMSQ (Short } \\
\text { Portable Mental Status } \\
\text { Questionaire) } \\
\text { - Structured Clinical } \\
\text { Interview for the } \\
\text { DSM-IV } \\
\text { - Caregiver Burden } \\
\text { Scale }\end{array}$ & $\begin{array}{l}\text { - 19,9\% dos cuidadores } \\
\text { reportaram ter visto o paciente } \\
\text { "confuso, delirante" pelo menos } \\
\text { uma vez por semana no mês } \\
\text { anterior ao estudo; } \\
\text { - cuidadores que percebiam o } \\
\text { doente confuso ou delirante } \\
\text { tinham } 12 \text { vezes mais } \\
\text { probabilidades de ter ansiedade } \\
\text { generalizada; } \\
\text { - houve uma associação } \\
\text { estatisticamente significativa } \\
\text { entre a percepção de delírio } \\
\text { nos pacientes por parte dos } \\
\text { cuidadores e a sua sobrecarga; } \\
\text { - a sobrecarga do cuidador esteve } \\
\text { também fortemente associada à } \\
\text { ansiedade generalizada. }\end{array}$ \\
\hline $\begin{array}{l}\text { Caqueo- } \\
\text { Urízar } \\
\text { et al. } \\
(2013)^{33} \\
\text { Chile }\end{array}$ & $\begin{array}{l}\text { Avaliar o impacto da } \\
\text { figura do cuidador } \\
\text { primário na qualidade } \\
\text { de vida de pacientes } \\
\text { com câncer avançado. }\end{array}$ & $\begin{array}{l}\text { Quantitativo, } \\
\text { transversal }\end{array}$ & $\begin{array}{l}34 \text { pacientes } \\
\text { com câncer } \\
\text { avançado e seus } \\
\text { cuidadores }\end{array}$ & $\begin{array}{l}\text {-FACT-G (Functional } \\
\text { Assessment of Cancer } \\
\text { Therapy) } \\
\text { - SF-36 } \\
\text { - Escala de Sobrecarga } \\
\text { de Zarit }\end{array}$ & $\begin{array}{l}\text {-Os cuidadores avaliam } \\
\text { positivamente a sua qualidade } \\
\text { de vida; } \\
\text { - cuidadores de pacientes em } \\
\text { estádio mais avançado da doença } \\
\text { apresentam um leve grau de } \\
\text { sobrecarga nas áreas física, social, } \\
\text { psíquica e econômica. }\end{array}$ \\
\hline $\begin{array}{l}\text { Castillo } \\
\text { et al. } \\
(2008)^{34} \\
\text { México }\end{array}$ & $\begin{array}{l}\text { Medir e comparar os } \\
\text { níveis de sobrecarga, } \\
\text { ansiedade e depressão } \\
\text { em cuidadores de } \\
\text { pacientes com dor } \\
\text { crônica com o de } \\
\text { cuidadores de doentes } \\
\text { terminais. }\end{array}$ & $\begin{array}{l}\text { Quantitativo, } \\
\text { transversal }\end{array}$ & $\begin{array}{l}65 \text { cuidadores } \\
\text { primários de } \\
\text { pacientes com } \\
\text { dor crônica e } \\
35 \text { cuidadores } \\
\text { de doentes } \\
\text { terminais }\end{array}$ & $\begin{array}{l}\text { - Escala de Sobrecarga } \\
\text { de Zarit, - Inquérito } \\
\text { de Saúde do cuidador } \\
\text { informal } \\
\text { - História clínica } \\
\text { multimodal de } \\
\text { Lazarus }\end{array}$ & $\begin{array}{l}\text { - ambos os grupos ultrapassaram } \\
\text { o ponto de corte de sobrecarga, } \\
\text { sem diferenças significativas } \\
\text { entre os grupos com relação a } \\
\text { sobrecarga e ansiedade; } \\
\text { - cuidadores de doentes } \\
\text { terminais apresentaram maior } \\
\text { sintomatologia depressiva e maior } \\
\text { impacto percebido no humor; } \\
\text { - foram encontradas correlações } \\
\text { positivas e estatisticamente } \\
\text { significativas entre sobrecarga } \\
\text { e depressão; sobrecarga e } \\
\text { ansiedade; e depressão e } \\
\text { ansiedade. }\end{array}$ \\
\hline
\end{tabular}

Relativamente ao desenho dos estudos, a maioria dos artigos selecionados era quantitativa, dois mistos e apenas um qualitativo. Dos 24 estudos quantitativos, 17 eram transversais e sete longitudinais, sendo estes últimos constituídos por dois estudos que realizaram avaliações exclusivamente durante a doença do familiar ${ }^{29,35,36}$ e cinco estudos que avaliaram os familiares tanto durante a fase de prestação de cuidados ao paciente quanto após o óbito do mesmo ${ }^{19,28,37-39}$. 
Quadro 1. continuação

\begin{tabular}{|c|c|c|c|c|c|}
\hline $\begin{array}{c}\text { Autor/ano } \\
\text { País }\end{array}$ & Objetivo & $\begin{array}{l}\text { Desenho } \\
\text { estudo }\end{array}$ & População & $\begin{array}{c}\text { Instrumentos } \\
\text { utilizados }\end{array}$ & $\begin{array}{c}\text { Resumo } \\
\text { dos resultados }\end{array}$ \\
\hline $\begin{array}{l}\text { Chang } \\
\text { et al. } \\
(2013)^{39} \\
\text { Coreia }\end{array}$ & $\begin{array}{l}\text { Determinar a } \\
\text { sobrecarga dos } \\
\text { pacientes e cuidadores } \\
\text { e quais os fatores são } \\
\text { mais importantes para } \\
\text { a satisfação com os } \\
\text { cuidados. }\end{array}$ & $\begin{array}{l}\text { Quantitativo, } \\
\text { longitudinal } \\
4 \text { avaliações: } \\
\text { T0 - } \\
\text { diagnóstico } \\
\text { câncer } \\
\text { terminal } \\
\text { T1 - } 1 \text { mês, } \\
\text { T2 - } 2 \text { meses } \\
\text { e } \\
\text { T3 - } 3 \text { meses } \\
\text { após óbito } \\
\text { paciente }\end{array}$ & $\begin{array}{l}481 \text { pacientes } \\
\text { com câncer } \\
\text { terminal e } 381 \\
\text { cuidadores }\end{array}$ & $\begin{array}{l}\text { - Questionário } \\
\text { construído pelos } \\
\text { autores que avalia: } \\
\text { respostas emocionais } \\
\text { e atitudes em relação } \\
\text { à divulgação do } \\
\text { diagnóstico, qualidade } \\
\text { de vida, sobrecarga e } \\
\text { satisfação geral com os } \\
\text { cuidados. }\end{array}$ & $\begin{array}{l}\text { - cuidadores apresentaram maior } \\
\text { nível de sobrecarga do que os } \\
\text { pacientes; } \\
\text { - a sobrecarga dos cuidadores e } \\
\text { o bom } \\
\text { funcionamento da família } \\
\text { influenciaram na satisfação com o } \\
\text { cuidado em geral; } \\
\text { - para os pacientes, o seu o } \\
\text { estado de saúde e a sobrecarga } \\
\text { influenciaram na satisfação com o } \\
\text { cuidado em geral; } \\
\text { - sobrecarga foi o fator de } \\
\text { maior previsão de satisfação } \\
\text { com o cuidado geral, tanto para } \\
\text { os pacientes quanto para os } \\
\text { cuidadores. }\end{array}$ \\
\hline $\begin{array}{l}\text { Costa- } \\
\text { Requena } \\
\text { et al. } \\
(2012)^{40} \\
\text { Espanha }\end{array}$ & $\begin{array}{l}\text { Avaliar o distress } \\
\text { psicológico dos } \\
\text { cuidadores de } \\
\text { pacientes com uma } \\
\text { doença avançada e/ } \\
\text { ou terminal internado } \\
\text { em uma unidade de } \\
\text { cuidados paliativos. }\end{array}$ & $\begin{array}{l}\text { Quantitativo, } \\
\text { transversal }\end{array}$ & $\begin{array}{l}179 \text { cuidadores } \\
\text { de pacientes } \\
\text { internados em } \\
\text { uma unidade } \\
\text { de cuidados } \\
\text { paliativos }\end{array}$ & $\begin{array}{l}\text { - Escala de Sobrecarga } \\
\text { de Zarit } \\
\text { - HADS (Hospital } \\
\text { Anxiety and } \\
\text { Depression Scale) } \\
\text { - Rosenberg self- } \\
\text { esteem scale }\end{array}$ & $\begin{array}{l}\text { - } 77 \% \text { dos cuidadores relataram } \\
\text { distress significativo, ansiedade } \\
(76,1 \%) \text { e depressão }(77,4 \%) ; \\
\text { - 52,3\% dos participantes } \\
\text { tinham sintomas de sobrecarga } \\
\text { significativa; } \\
\text { - cuidadores com elevada } \\
\text { autoestima parecem ser menos } \\
\text { angustiados e tendem a ser menos } \\
\text { sobrecarregados; } \\
\text { - nível de distress dos } \\
\text { cuidadores estava associado } \\
\text { significativamente com a } \\
\text { sobrecarga do cuidador. }\end{array}$ \\
\hline $\begin{array}{l}\text { Dumont } \\
\text { et al. } \\
(2006)^{35} \\
\text { Canadá }\end{array}$ & $\begin{array}{l}\text { Determinar o grau } \\
\text { em que o distress } \\
\text { psicológico dos } \\
\text { cuidadores familiares } \\
\text { é influenciado pelo } \\
\text { estado funcional do } \\
\text { paciente. }\end{array}$ & $\begin{array}{l}\text { Quantitativo, } \\
\text { longitudinal } \\
\text { até } 3 \\
\text { avaliações } \\
\text { de acordo } \\
\text { com o estado } \\
\text { funcional do } \\
\text { paciente }\end{array}$ & $\begin{array}{l}212 \text { cuidadores } \\
\text { divididos } \\
\text { em } 3 \text { grupos } \\
\text { de acordo } \\
\text { com o estado } \\
\text { funcional do } \\
\text { paciente }\end{array}$ & $\begin{array}{l}\text { - IDPESQ (Indice de } \\
\text { détresse psychologique } \\
\text { de Santé Québec) } \\
\text { - Psychiatric } \\
\text { Symptoms Index } \\
\text { - SDS (Symptom } \\
\text { Distress Scale) } \\
\text { - HCNS (Home } \\
\text { Caregivers Need } \\
\text { Survey) }\end{array}$ & $\begin{array}{l}\text { - cuidadores apresentaram } \\
\text { um elevado nível de distress } \\
\text { psicológico ( } 41 \% \text { a } 62 \%) ; \\
\text { - distress psicossocial dos } \\
\text { cuidadores familiares foi } \\
\text { fortemente associado com } \\
\text { o progresso da doença dos } \\
\text { pacientes terminais e o declínio } \\
\text { do estado funcional; } \\
\text { - alto índice de distress } \\
\text { psicológico do cuidador foi } \\
\text { significativamente associado } \\
\text { com idade jovem do paciente, } \\
\text { sintomas do paciente, a } \\
\text { sobrecarga do cuidador, } \\
\text { cuidadores mais jovens e do sexo } \\
\text { feminino, pior percepção da sua } \\
\text { saúde, insatisfação com apoio } \\
\text { disponível dos amigos e com o } \\
\text { apoio emocional. }\end{array}$ \\
\hline
\end{tabular}




\begin{tabular}{|c|c|c|c|c|c|}
\hline \multicolumn{6}{|c|}{ Quadro 1. continuação } \\
\hline $\begin{array}{c}\text { Autor/ano } \\
\text { País }\end{array}$ & Objetivo & $\begin{array}{l}\text { Desenho } \\
\text { estudo }\end{array}$ & População & $\begin{array}{l}\text { Instrumentos } \\
\text { utilizados }\end{array}$ & $\begin{array}{c}\text { Resumo } \\
\text { dos resultados }\end{array}$ \\
\hline $\begin{array}{l}\text { Ferrario } \\
\text { et al. } \\
(2004)^{19} \\
\text { Itália }\end{array}$ & $\begin{array}{l}\text { Contribuir para } \\
\text { melhorar a } \\
\text { compreensão dos } \\
\text { problemas vivenciados } \\
\text { pelos cuidadores de } \\
\text { pacientes com câncer } \\
\text { em fase avançada ou } \\
\text { terminal durante o } \\
\text { período da prestação } \\
\text { de cuidados e no luto. }\end{array}$ & $\begin{array}{l}\text { Quantitativo, } \\
\text { longitudinal, } \\
4 \text { avaliações: } \\
\text { T0: período } \\
\text { de doença, } \\
\text { T1:3 meses, } \\
\text { T2:6 meses, e } \\
\text { T3:12 meses } \\
\text { após óbito } \\
\text { do paciente }\end{array}$ & $\begin{array}{l}93 \text { cuidadores } \\
\text { familiares } \\
\text { de pacientes } \\
\text { acompanhados } \\
\text { em casa } \\
\text { com câncer } \\
\text { avançado / } \\
\text { terminal }\end{array}$ & $\begin{array}{l}\text { - CBA 2.0 (Cognitive } \\
\text { Assessment } \\
\text { Comportamental) } \\
\text { - FSQ (Family Strain } \\
\text { Questionnaire) } \\
\text { - SWLS (Satisfaction } \\
\text { with Life Scale) } \\
\text { - ECOG-PS } \\
\text { - CMQ (Caregiver } \\
\text { Mourning } \\
\text { Questionnaire) }\end{array}$ & $\begin{array}{l}\text { - desajustamento no luto foi } \\
\text { correlacionado com a percepção } \\
\text { de distress emocional e problemas } \\
\text { relacionados ao cuidar detectados } \\
\text { no momento de referenciação, } \\
\text { principalmente nas mulheres; } \\
\text { - cônjuges, cuidadores com } \\
\text { mais de } 61 \text { anos e aqueles que } \\
\text { percebiam uma sobrecarga } \\
\text { emocional substancial } \\
\text { estavam em maior risco de } \\
\text { desajustamento no luto a longo } \\
\text { prazo; } \\
\text { - menor satisfação com a vida } \\
\text { na presença de percepção de } \\
\text { sobrecarga emocional; } \\
\text { - mulheres apresentaram escores } \\
\text { significativamente mais altos } \\
\text { de sobrecarga emocional e de } \\
\text { sintomas depressivos. }\end{array}$ \\
\hline $\begin{array}{l}\text { Fleming } \\
\text { et al. } \\
(2006)^{41} \\
\text { EUA }\end{array}$ & $\begin{array}{l}\text { Explorar a associação } \\
\text { entre a percepção } \\
\text { da qualidade dos } \\
\text { cuidados de saúde e } \\
\text { qualidade de vida em } \\
\text { pacientes com câncer } \\
\text { metastático avançado } \\
\text { e seus cuidadores } \\
\text { informais. }\end{array}$ & $\begin{array}{l}\text { Quantitativo, } \\
\text { transversal }\end{array}$ & $\begin{array}{l}39 \text { pacientes } \\
\text { com câncer } \\
\text { avançado e } \\
\text { seus cuidadores } \\
\text { informais }\end{array}$ & $\begin{array}{l}\text { - CES-D (Center for } \\
\text { Epidemiologic Studies } \\
\text { Depression Scale) } \\
\text { - SF-12 } \\
\text { - PCAS } \\
\text { - MSAS-SF (Memorial } \\
\text { Symptom Assessment } \\
\text { Scale-Short Form) } \\
\text { - FAC (Feelings About } \\
\text { Caregiving ) }\end{array}$ & $\begin{array}{l}\text { - cuidadores relataram um nível } \\
\text { moderado de sobrecarga e um } \\
\text { nível relativamente elevado de } \\
\text { satisfação com o cuidado; } \\
\text { - saúde mental dos pacientes } \\
\text { e os escores de depressão dos } \\
\text { cuidadores estão correlacionados; } \\
\text { - pacientes e cuidadores } \\
\text { compartilham percepções } \\
\text { semelhantes em relação à } \\
\text { qualidade dos cuidados de saúde; } \\
\text { - a presença de depressão nos } \\
\text { cuidadores estava correlacionada } \\
\text { com a menor satisfação dos } \\
\text { cuidadores com os cuidados de } \\
\text { saúde que estão sendo prestados } \\
\text { aos seus familiares. }\end{array}$ \\
\hline $\begin{array}{l}\text { Fried et al. } \\
(2005)^{42} \\
\text { EUA }\end{array}$ & $\begin{array}{l}\text { Analisar a adequação } \\
\text { da comunicação } \\
\text { cuidador-paciente } \\
\text { com doença grave } \\
\text { e sua relação com } \\
\text { a sobrecarga do } \\
\text { cuidador. }\end{array}$ & $\begin{array}{l}\text { Quantitativo, } \\
\text { transversal }\end{array}$ & $\begin{array}{l}193 \text { pacientes } \\
\text { com mais } \\
\text { de } 60 \text { anos } \\
\text { com câncer } \\
\text { avançado, } \\
\text { insuficiência } \\
\text { cardíaca } \\
\text { congestiva, } \\
\text { ou doença } \\
\text { pulmonar } \\
\text { crônica e seus } \\
\text { cuidadores. }\end{array}$ & $\begin{array}{l}\text { - Escala de Sobrecarga } \\
\text { de Zarit } \\
\text { - Escala sobre } \\
\text { comunicação } \\
\text { construída pelos } \\
\text { autores }\end{array}$ & $\begin{array}{l}\text { - 39,9\% dos cuidadores } \\
\text { desejavam mais comunicação, } \\
\text { e } 37,3 \% \text { relataram que a } \\
\text { comunicação era difícil; } \\
\text { - dos pacientes, } 20,2 \% \text { desejavam } \\
\text { mais comunicação, e } 22,3 \% \\
\text { relataram que a comunicação era } \\
\text { difícil; } \\
\text { - os cuidadores que desejavam } \\
\text { mais comunicação tiveram níveis } \\
\text { significativamente mais elevados } \\
\text { de sobrecarga no cuidar do que os } \\
\text { cuidadores que não desejavam. }\end{array}$ \\
\hline
\end{tabular}


Quadro 1. continuação

\begin{tabular}{|c|c|c|c|c|c|}
\hline $\begin{array}{c}\text { Autor/ano } \\
\text { País }\end{array}$ & Objetivo & $\begin{array}{l}\text { Desenho } \\
\text { estudo }\end{array}$ & População & $\begin{array}{c}\text { Instrumentos } \\
\text { utilizados }\end{array}$ & $\begin{array}{c}\text { Resumo } \\
\text { dos resultados }\end{array}$ \\
\hline $\begin{array}{l}\text { Grov et al. } \\
(2006)^{43} \\
\text { Noruega }\end{array}$ & $\begin{array}{l}\text { Examinar as } \\
\text { associações } \\
\text { entre ansiedade } \\
\text { e depressão com } \\
\text { a sobrecarga do } \\
\text { cuidador por meio } \\
\text { da path-analysis. }\end{array}$ & $\begin{array}{l}\text { Quantitativo, } \\
\text { Transversal, }\end{array}$ & $\begin{array}{l}96 \text { cuidadores } \\
\text { de pacientes } \\
\text { com câncer em } \\
\text { fase paliativa } \\
\text { cuidados em } \\
\text { casa }\end{array}$ & $\begin{array}{l}\text { - CRA } \\
\text { - SF-36 } \\
\text { - HADS } \\
\text { - SPS (Social } \\
\text { Provisions Scale) }\end{array}$ & $\begin{array}{l}\text { - depressão apresentou associação } \\
\text { direta e significativa com a } \\
\text { sobrecarga do cuidador; } \\
\text { - apoio social não foi } \\
\text { significativamente associado com } \\
\text { a ansiedade ou com a sobrecarga } \\
\text { do cuidador; } \\
\text { - Saúde física dos cuidadores } \\
\text { estava associada significativa com } \\
\text { a ansiedade e depressão, mas não } \\
\text { com a sobrecarga do cuidador. }\end{array}$ \\
\hline $\begin{array}{l}\text { Grunfeld } \\
\text { et al. } \\
(2004)^{36} \\
\text { Canadá }\end{array}$ & $\begin{array}{l}\text { Avaliar o impacto } \\
\text { psicossocial, } \\
\text { ocupacional e } \\
\text { econômico de cuidar } \\
\text { de uma pessoa } \\
\text { com uma doença } \\
\text { terminal. }\end{array}$ & $\begin{array}{l}\text { Quantitativo, } \\
\text { longitudinal, } \\
\text { pacientes e } \\
\text { familiares } \\
\text { foram } \\
\text { acompanhados } \\
\text { até a morte do } \\
\text { paciente ou por } \\
3 \text { anos }\end{array}$ & $\begin{array}{l}89 \text { cuidadores } \\
\text { de mulheres } \\
\text { com câncer de } \\
\text { mama avançado }\end{array}$ & $\begin{array}{l}\text { - KPS } \\
\text { - SF-36 } \\
\text { - HADS } \\
\text { - Escala de Sobrecarga } \\
\text { de Zarit } \\
\text { - FAMCARE } \\
\text { - Medical Outcomes } \\
\text { Study Social Support } \\
\text { Survey }\end{array}$ & $\begin{array}{l}\text { - significativamente mais } \\
\text { cuidadores do que doentes } \\
\text { estavam ansiosos; } \\
\text { - cuidadores estavam deprimidos } \\
\text { e tinham um nível mais elevado } \\
\text { de sobrecarga; } \\
\text { - sobrecarga do cuidador foi o } \\
\text { preditor mais importante da } \\
\text { ansiedade e depressão; } \\
\text { - depressão e a sobrecarga } \\
\text { percebida dos cuidadores } \\
\text { aumentaram como o declínio do } \\
\text { estado funcional dos pacientes. }\end{array}$ \\
\hline $\begin{array}{l}\text { Harding } \\
\text { et al. } \\
(2003)^{18} \\
\text { Inglaterra }\end{array}$ & $\begin{array}{l}\text { Identificar quais } \\
\text { características } \\
\text { dos pacientes } \\
\text { contribuem para o } \\
\text { distress psicológico } \\
\text { do cuidador e quais } \\
\text { estratégias de coping } \\
\text { são empregadas } \\
\text { pelos cuidadores. }\end{array}$ & $\begin{array}{l}\text { Quantitativo, } \\
\text { transversal }\end{array}$ & $\begin{array}{l}43 \text { cuidadores } \\
\text { de pacientes } \\
\text { em cuidados } \\
\text { paliativos }\end{array}$ & $\begin{array}{l}\text { - POS (Palliative } \\
\text { Outcome Scale) } \\
\text { - ECOG } \\
\text { - Escala de Sobrecarga } \\
\text { de Zarit } \\
\text { - CRI (Coping } \\
\text { Responses Inventory) } \\
\text { - GHQ- } 12 \\
\text { - SAI }\end{array}$ & $\begin{array}{l}\text { - maior distress do paciente foi } \\
\text { associado a maior ansiedade do } \\
\text { cuidador; } \\
\text { - dor e pior estado psicológico } \\
\text { dos doentes foram associados } \\
\text { positivamente com a morbilidade } \\
\text { psicológica do cuidador; } \\
\text { - aumento da sobrecarga do } \\
\text { cuidador foi associado ao } \\
\text { aumento do distress psicológico e } \\
\text { da dor do paciente. }\end{array}$ \\
\hline $\begin{array}{l}\text { Hwang } \\
\text { et al. } \\
(2003)^{44} \\
\text { EUA }\end{array}$ & $\begin{array}{l}\text { Identificar e avaliar } \\
\text { as associações entre } \\
\text { as características dos } \\
\text { cuidadores e as suas } \\
\text { necessidades não } \\
\text { satisfeitas, sobrecarga } \\
\text { e satisfação no } \\
\text { cuidar. }\end{array}$ & $\begin{array}{l}\text { Quantitativo, } \\
\text { transversal }\end{array}$ & $\begin{array}{l}100 \text { cuidadores } \\
\text { de pacientes } \\
\text { com câncer } \\
\text { avançado }\end{array}$ & $\begin{array}{l}\text { - FIN (Family } \\
\text { Inventory of Needs) } \\
\text { - CSI (Care Strain } \\
\text { Index) } \\
\text { - FAMCARE } \\
\text { - PPUN } \\
\text { - GDSSF } \\
\text { - EQ-5D } \\
\text { - Duke-UNC } \\
\text { - DUFSS }\end{array}$ & $\begin{array}{l}\text { - a maioria das necessidades não } \\
\text { atendidas foi relacionada com } \\
\text { as necessidades de informação e } \\
\text { gestão dos sintomas; } \\
\text { - cônjuges cuidadores eram } \\
\text { significativamente mais } \\
\text { velhos, com pontuações } \\
\text { mais elevadas de depressão e } \\
\text { sobrecarga, e menores escores de } \\
\text { apoio social do que os cuidadores } \\
\text { não cônjuges; } \\
\text { - cuidadores com uma maior } \\
\text { percepção de necessidades não } \\
\text { satisfeitas do paciente e maior } \\
\text { nível de depressão apresentavam } \\
\text { maior sobrecarga. }\end{array}$ \\
\hline
\end{tabular}


Quadro 1. continuação

\begin{tabular}{|c|c|c|c|c|c|}
\hline $\begin{array}{l}\text { Autor/ano } \\
\text { País }\end{array}$ & Objetivo & $\begin{array}{c}\text { Desenho } \\
\text { estudo }\end{array}$ & População & $\begin{array}{c}\text { Instrumentos } \\
\text { utilizados }\end{array}$ & $\begin{array}{c}\text { Resumo } \\
\text { dos resultados }\end{array}$ \\
\hline $\begin{array}{l}\text { Kang et al. } \\
(2013)^{23} \\
\text { Coreia }\end{array}$ & $\begin{array}{l}\text { Identificar } \\
\text { como o luto e a } \\
\text { sobrecarga afetam } \\
\text { as consequências } \\
\text { positivas nos } \\
\text { cuidadores familiares } \\
\text { de pacientes com } \\
\text { câncer terminal. }\end{array}$ & $\begin{array}{l}\text { Quantitativo, } \\
\text { transversal }\end{array}$ & $\begin{array}{l}501 \text { cuidadores } \\
\text { enlutados de } \\
\text { pacientes com } \\
\text { câncer terminal, } \\
\text { que faleceram } \\
\text { entre } 2 \text { e } 6 \\
\text { meses }\end{array}$ & $\begin{array}{l}\text { - CCI (Caregiving } \\
\text { Consequences } \\
\text { Inventory) }\end{array}$ & $\begin{array}{l}\text { - os cuidadores familiares } \\
\text { enlutados relataram altos níveis } \\
\text { de ganhos percebidos e de } \\
\text { sobrecarga; } \\
\text { - depressão do cuidador ou } \\
\text { sobrecarga percebida não } \\
\text { afetaram as consequências } \\
\text { positivas da prestação de } \\
\text { cuidados; } \\
\text { - receber acompanhamento no } \\
\text { luto por profissionais de cuidados } \\
\text { paliativos foi significativamente } \\
\text { associado com os resultados } \\
\text { positivos dos ganhos percebidos. }\end{array}$ \\
\hline $\begin{array}{l}\text { Kapari } \\
\text { et al. } \\
(2010)^{37} \\
\text { Inglaterra }\end{array}$ & $\begin{array}{l}\text { Estabelecer relações } \\
\text { entre os sintomas de } \\
\text { TMC (transtorno } \\
\text { mental comum) } \\
\text { em cuidadores } \\
\text { de pacientes com } \\
\text { doença avançada, } \\
\text { durante a fase } \\
\text { de prestação de } \\
\text { cuidados e no luto. }\end{array}$ & $\begin{array}{l}\text { Quantitativo, } \\
\text { longitudinal, } 3 \\
\text { avaliações: } \\
\text { T0: período de } \\
\text { doença, } \\
\text { T1: 3meses e } \\
\text { T2: } 6 \text { meses } \\
\text { após o óbito do } \\
\text { paciente }\end{array}$ & $\begin{array}{l}100 \\
\text { cuidadores } \\
\text { familiares } \\
\text { de doentes } \\
\text { em cuidados } \\
\text { paliativos }\end{array}$ & $\begin{array}{l}\text { - HADS } \\
\text { - CIS-R } \\
\text { - CBI } \\
\text { - WSAS } \\
\text { - SOS } \\
\text {-FACES III } \\
\text {-Royal Free Interview } \\
\text { for Spiritual and } \\
\text { Religious Beliefs } \\
\text { - BriefCOPE } \\
\text { - QOD } \\
\text { - BPQ }\end{array}$ & $\begin{array}{l}\text { - os cuidadores que perceberam } \\
\text { a sua experiência como sendo } \\
\text { de maior sobrecarga tiveram } \\
\text { mais sintomas de TMC enquanto } \\
\text { cuidavam do seu familiar; } \\
\text {-Saúde mental do cuidador } \\
\text { durante a experiência de cuidado } \\
\text { foi preditiva da sua saúde mental, } \\
\text { três e seis meses após a morte do } \\
\text { paciente; } \\
\text { - cuidadores com mais sintomas } \\
\text { de TMC na primeira avaliação } \\
\text { eram mais susceptíveis de piores } \\
\text { resultados no luto aos três e aos } \\
\text { seis meses após a perda o que } \\
\text { sugere um luto mais complicado. }\end{array}$ \\
\hline $\begin{array}{l}\text { Kim et al. } \\
(2014)^{45} \\
\text { Coreia do } \\
\text { Sul }\end{array}$ & $\begin{array}{l}\text { Investigar os } \\
\text { determinantes } \\
\text { da atitude de } \\
\text { esperança entre os } \\
\text { cuidadores familiares } \\
\text { de pacientes em } \\
\text { cuidados paliativos. }\end{array}$ & $\begin{array}{l}\text { Quantitativo, } \\
\text { transversal }\end{array}$ & $\begin{array}{l}304 \text { pacientes e } \\
\text { seus cuidadores }\end{array}$ & $\begin{array}{l}\text { - BHS-7 } \\
\text { - MADRS } \\
\text { - SCQ } \\
\text { - ZBI-7 (Escala de } \\
\text { Sobrecarga de Zarit } \\
\text { reduzida) } \\
\text { - DRI }\end{array}$ & $\begin{array}{l}\text { - } 69,1 \% \text { dos cuidadores } \\
\text { mostraram uma atitude de } \\
\text { esperança; } \\
\text { - a atitude de esperança nos } \\
\text { cuidadores foi correlacionada } \\
\text { com o seu estado psicológico } \\
\text { (menos sintomas depressivos), } \\
\text { estratégia de coping ativo, menor } \\
\text { sobrecarga e maior religiosidade. }\end{array}$ \\
\hline $\begin{array}{l}\text { Lai et al. } \\
(2014)^{46} \\
\text { Itália }\end{array}$ & $\begin{array}{l}\text { Testar se os altos } \\
\text { níveis de sobrecarga } \\
\text { do cuidador, e } \\
\text { outros preditores, } \\
\text { estão associados } \\
\text { com o risco de } \\
\text { luto prolongado } \\
\text { em cuidadores de } \\
\text { pacientes terminais. }\end{array}$ & $\begin{array}{l}\text { Quantitativo, } \\
\text { transversal }\end{array}$ & $\begin{array}{l}60 \text { cuidadores } \\
\text { de pacientes } \\
\text { internados em } \\
\text { um hospice }\end{array}$ & $\begin{array}{l}\text {-PG-12 } \\
\text { - Toronto Alexithymia } \\
\text { Scale } \\
\text { - Hamilton Anxiety } \\
\text { Rating Scale } \\
\text { - Hamilton Depression } \\
\text { Rating Scale } \\
\text { - CBI (Caregiver } \\
\text { Burden Inventory) }\end{array}$ & $\begin{array}{l}\text { - cuidadores do sexo feminino } \\
\text { apresentaram um risco mais } \\
\text { elevado de luto prolongado do } \\
\text { que os cuidadores masculinos; } \\
\text { - o grau de risco de luto } \\
\text { prolongado (PG-12) foi } \\
\text { correlacionado com a alexitimia, } \\
\text { ansiedade, depressão, sobrecarga } \\
\text { física, social e emocional; } \\
\text { - a sobrecarga elevada aumenta a } \\
\text { possibilidade de luto prolongado. }\end{array}$ \\
\hline
\end{tabular}




\begin{tabular}{|c|c|c|c|c|c|}
\hline \multicolumn{6}{|c|}{ Quadro 1. continuação } \\
\hline $\begin{array}{l}\text { Autor/ano } \\
\text { País }\end{array}$ & Objetivo & $\begin{array}{l}\text { Desenho } \\
\text { estudo }\end{array}$ & População & $\begin{array}{c}\text { Instrumentos } \\
\text { utilizados }\end{array}$ & $\begin{array}{c}\text { Resumo } \\
\text { dos resultados }\end{array}$ \\
\hline $\begin{array}{l}\text { Ling et al. } \\
(2013)^{38} \\
\text { Taiwan }\end{array}$ & $\begin{array}{l}\text { Explorar a } \\
\text { ocorrência de } \\
\text { sintomas depressivos } \\
\text { e fatores que afetam } \\
\text { os cuidadores } \\
\text { familiares antes e } \\
\text { depois da morte do } \\
\text { familiar com câncer. }\end{array}$ & $\begin{array}{l}\text { Quantitativo, } \\
\text { longitudinal, } \\
5 \text { avaliações, } \\
\text { do período } \\
\text { de doença } \\
\text { até } 13 \text { meses } \\
\text { após óbito do } \\
\text { paciente }\end{array}$ & $\begin{array}{l}186 \text { familiares } \\
\text { cuidadores } \\
\text { de pacientes } \\
\text { oncológicos }\end{array}$ & $\begin{array}{l}\text { - CES-D (Center for } \\
\text { Epidemiologic Studies } \\
\text { Depression Scale) } \\
\text { - MOS-SSS (Medical } \\
\text { Outcomes Study } \\
\text { Social Support } \\
\text { Survey) } \\
\text { - CRA }\end{array}$ & $\begin{array}{l}\text { - cuidadores enlutados que } \\
\text { apresentaram menos sintomas } \\
\text { depressivos tinham cuidado de } \\
\text { doentes mais velhos, relatado } \\
\text { um maior nível de sobrecarga } \\
\text { subjetiva durante o fim de vida } \\
\text { do paciente e tinham mais apoio } \\
\text { social; } \\
\text { - cuidadores que relataram mais } \\
\text { sintomas depressivos no luto } \\
\text { tiveram também mais sintomas } \\
\text { depressivos antes da morte do } \\
\text { doente, uma saúde mais precária } \\
\text { e eram cônjuges dos pacientes. }\end{array}$ \\
\hline $\begin{array}{l}\text { Payne et } \\
\text { al. } \\
(1999)^{9} \\
\text { Inglaterra }\end{array}$ & $\begin{array}{l}\text { Identificar as } \\
\text { necessidades de } \\
\text { apoio percebido } \\
\text { pelos cuidadores } \\
\text { informais de } \\
\text { pacientes com } \\
\text { câncer que recebem } \\
\text { cuidados paliativos } \\
\text { na comunidade. }\end{array}$ & $\begin{array}{l}\text { Misto, } \\
\text { (quantitativo } \\
\text { e qualitativo), } \\
\text { transversal }\end{array}$ & $\begin{array}{l}39 \text { cuidadores } \\
\text { de pacientes } \\
\text { com câncer } \\
\text { acompanhados } \\
\text { em cuidados } \\
\text { paliativos }\end{array}$ & $\begin{array}{l}\text { - General Health } \\
\text { Questionnaire } \\
\text { - Care Strain Index } \\
\text { - Entrevista } \\
\text { semiestruturada para } \\
\text { avaliar as percepções } \\
\text { do cuidar }\end{array}$ & $\begin{array}{l}\text { - } 84 \% \text { dos cuidadores relataram } \\
\text { níveis acima dos normais de } \\
\text { distress psicológico; } \\
\text { - } 41 \% \text { apresentaram níveis } \\
\text { elevados de tensão relacionados } \\
\text { com a prestação de cuidados; } \\
\text { - a maioria dos cuidadores } \\
\text { relataram sobrecarga no cuidar; } \\
\text { - cuidadores mais jovens e do } \\
\text { sexo feminino apresentaram } \\
\text { níveis mais elevados de distress } \\
\text { psicológico e sobrecarga no } \\
\text { cuidar. }\end{array}$ \\
\hline $\begin{array}{l}\text { Proot et al. } \\
(2003)^{47} \\
\text { Holanda }\end{array}$ & $\begin{array}{l}\text { Explorar as } \\
\text { experiências } \\
\text { dos cuidadores } \\
\text { familiares, as suas } \\
\text { necessidades para } \\
\text { cuidar do paciente } \\
\text { em casa, e quais } \\
\text { serviços de saúde } \\
\text { tem recebido. }\end{array}$ & $\begin{array}{l}\text { Qualitativo, } \\
\text { transversal }\end{array}$ & $\begin{array}{l}13 \text { cuidadores } \\
\text { familiares que } \\
\text { cuidam em casa } \\
\text { de pacientes } \\
\text { terminais }\end{array}$ & - Entrevista & $\begin{array}{l}\text { - Sobrecarga no cuidar, restrição } \\
\text { de atividades, medo, insegurança, } \\
\text { solidão, enfrentar a morte, falta } \\
\text { de apoio emocional, prático e de } \\
\text { informações foram identificados } \\
\text { como fatores que têm potencial } \\
\text { para aumentar a vulnerabilidade } \\
\text { do cuidador, e podem ser fatores } \\
\text { de risco para a fadiga e burnout; } \\
\text { - Continuar com as atividades } \\
\text { anteriores, esperança, manter o } \\
\text { controle, satisfação e bom suporte } \\
\text { social são fatores que podem } \\
\text { diminuir a vulnerabilidade do } \\
\text { cuidador, e proteger contra a } \\
\text { fadiga e o burnout. }\end{array}$ \\
\hline
\end{tabular}

continua

De acordo com os critérios de inclusão, os pacientes eram todos doentes oncológicos ou em cuidados paliativos. Em sete artigos, a população do estudo foi composta pelos pacientes e seus cuidadores $29,33,39,41,42,48,49$.
Com relação aos participantes, a maioria era de familiares do sexo feminino e cônjuges dos pacientes. Em dois estudos, a população foi constituída exclusivamente por cônjuges ${ }^{28,29}$. O tamanho da amostra variou entre 34 e 1108 cui- 


\begin{tabular}{|c|c|c|c|c|c|}
\hline \multicolumn{6}{|c|}{ Quadro 1. continuação } \\
\hline $\begin{array}{l}\text { Autor/ano } \\
\text { País }\end{array}$ & Objetivo & $\begin{array}{l}\text { Desenho } \\
\text { estudo }\end{array}$ & População & $\begin{array}{l}\text { Instrumentos } \\
\text { utilizados }\end{array}$ & $\begin{array}{c}\text { Resumo } \\
\text { dos resultados }\end{array}$ \\
\hline $\begin{array}{l}\text { Salmon } \\
\text { et al. } \\
(2005)^{50} \\
\text { EUA }\end{array}$ & \begin{tabular}{|l|} 
Comparar \\
cuidadores ativos \\
com cuidadores \\
enlutados e testar os \\
efeitos independentes \\
da autoaceitação, \\
significado, \\
proximidade e \\
conforto com o \\
cuidado para explicar \\
as diferenças de \\
ganho e sobrecarga \\
do cuidador.
\end{tabular} & $\begin{array}{l}\text { Quantitativo, } \\
\text { transversal }\end{array}$ & $\begin{array}{l}526 \text { cuidadores } \\
\text { ativos }(\mathrm{G} 1) \text { e } \\
427 \text { cuidadores } \\
\text { enlutados (G2) } \\
\text { de pacientes } \\
\text { acompanhados } \\
\text { em cuidados } \\
\text { paliativos }\end{array}$ & $\begin{array}{l}\text { - Revised Caregiving } \\
\text { Appraisal Scale } \\
\text { - Personal } \\
\text { growth subscale of } \\
\text { the Hogan Grief } \\
\text { Reaction Checklist } \\
\text { - Finding Meaning } \\
\text { Through Caregiving } \\
\text { - Questionário criado } \\
\text { pelos autores para } \\
\text { avaliar a proximidade } \\
\text { e nível de conforto } \\
\text { com as tarefas de } \\
\text { cuidar }\end{array}$ & $\begin{array}{l}\text { - cuidadores ativos relataram } \\
\text { níveis mais elevados de sobrecarga } \\
\text { e maior capacidade de atribuição } \\
\text { de significado; } \\
\text {-elevada sobrecarga foi associada } \\
\text { com o sexo feminino, pior estado } \\
\text { de saúde, cuidadores com ensino } \\
\text { superior, e com cuidadores de } \\
\text { pacientes que necessitam de mais } \\
\text { assistência nos cuidados; } \\
\text { - Menor sobrecarga foi associada } \\
\text { à recepção de apoio de outras } \\
\text { pessoas, capacidade de atribuir } \\
\text { um significado à experiência e se } \\
\text { sentir confortável com as tarefas } \\
\text { de cuidar; } \\
\text { - os cuidadores que estavam mais } \\
\text { confortáveis com a prestação de } \\
\text { cuidados apresentaram menor } \\
\text { sobrecarga e maior ganho } \\
\text { associado ao cuidar. }\end{array}$ \\
\hline $\begin{array}{l}\text { Tang et al. } \\
(2008)^{49} \\
\text { Taiwan }\end{array}$ & $\begin{array}{l}\text { Avaliar o impacto } \\
\text { do prognóstico e da } \\
\text { qualidade de vida } \\
\text { nos pacientes, o grau } \\
\text { de congruência entre } \\
\text { pacientes e familiares } \\
\text { sobre os cuidados } \\
\text { em fim de vida, e } \\
\text { a sobrecarga dos } \\
\text { cuidadores. }\end{array}$ & $\begin{array}{l}\text { Quantitativo } \\
\text { transversal }\end{array}$ & $\begin{array}{l}1108 \text { díades } \\
\text { paciente- } \\
\text { cuidador } \\
\text { familiar }\end{array}$ & $\begin{array}{l}\text { - MQLQ (McGill } \\
\text { Quality of Life } \\
\text { Questionnaire) } \\
\text { - Symptom } \\
\text { Distress Scale } \\
\text { - CRA }\end{array}$ & $\begin{array}{l}\text { - os cuidadores do estudo } \\
\text { prestavam uma considerável } \\
\text { assistência aos pacientes em todos } \\
\text { os aspectos do cuidado avaliados } \\
\text { no estudo e reportaram níveis } \\
\text { moderados de sobrecarga; } \\
\text { - a sobrecarga do cuidador teve um } \\
\text { impacto significativo na qualidade } \\
\text { de vida dos pacientes terminais, } \\
\text { ou seja, os cuidadores com maior } \\
\text { nível de sobrecarga influenciaram } \\
\text { negativamente na qualidade de } \\
\text { vida dos pacientes. }\end{array}$ \\
\hline $\begin{array}{l}\text { Wasner } \\
\text { et al. } \\
(2013)^{51} \\
\text { Alemanha }\end{array}$ & $\begin{array}{l}\text { Avaliar a experiência } \\
\text { pessoal dos } \\
\text { cuidadores de } \\
\text { pacientes com tumor } \\
\text { cerebral em relação } \\
\text { à qualidade de } \\
\text { vida, sobrecarga no } \\
\text { cuidar e bem-estar } \\
\text { psicológico. }\end{array}$ & $\begin{array}{l}\text { Misto, } \\
\text { quantitativo } \\
\text { e qualitativo, } \\
\text { transversal }\end{array}$ & $\begin{array}{l}27 \text { cuidadores } \\
\text { familiares de } \\
\text { pacientes com } \\
\text { tumor cerebral } \\
\text { acompanhados } \\
\text { em cuidados } \\
\text { paliativos }\end{array}$ & $\begin{array}{l}\text { - SEIQoL-DW } \\
\text { (Schedule for } \\
\text { the Evaluation of } \\
\text { Individual Quality } \\
\text { of Life-Direct } \\
\text { Weighting), } \\
\text { - BSFC-HADS } \\
\text { - Entrevista } \\
\text { semiestruturada }\end{array}$ & $\begin{array}{l}\text { - } 33 \% \text { dos cuidadores } \\
\text { apresentaram maior risco de } \\
\text { doenças psicossomáticas devido } \\
\text { à exaustão corporal, alterações } \\
\text { na qualidade de vida, distress } \\
\text { emocional, dificuldades financeiras } \\
\text { e outros fatores de sobrecarga; } \\
\text { - } 50 \% \text { dos cuidadores } \\
\text { apresentavam maiores níveis de } \\
\text { depressão e } 45 \% \text { de ansiedade; } \\
\text {-qualidade de vida do cuidador foi } \\
\text { fortemente } \\
\text { afetada pela sobrecarga no cuidar e } \\
\text { pelo estado mental deteriorado do } \\
\text { paciente; } \\
\text { - 41\% dos cuidadores reduziram } \\
\text { ou pararam de } \\
\text { trabalhar para cuidar do seu } \\
\text { familiar. }\end{array}$ \\
\hline
\end{tabular}


dadores familiares nos estudos quantitativos, entre treze e trinta e nove nos estudos qualitativos e mistos, e a idade média variou entre 46,8 e 68 anos (Quadro 1).

$\mathrm{O}$ instrumento mais utilizado para avaliar a sobrecarga foi a Escala de Sobrecarga de Zarit (Zarit Burden Interview), utilizada em sete estudos. A Caregiver Reaction Assessment (CRA) foi usada em quatro estudos, e a Care Strain Index (CSI) e a Caregiving Burden Scale (CBS) foram utilizadas em dois estudos cada uma. Outros instrumentos também empregados para a avaliação da sobrecarga foram: Family Strain Questionnaire (FSQ), Caregiving Burden Interview, Revised Caregiving Appraisal Scale, Caregiving Consequences Inventory (CCI), Caregiver Difficulties Questionnaire (CDQ), Caregiver Burden Inventory, Caregiver's Burden Scale in End-of-Life Care (CBS-EOLC), The Feelings About Caregiving (FAC), Burden Scale for Family Caregivers (BSFC).

Em relação às características sociodemográficas dos cuidadores, três estudos referiram que as mulheres apresentavam níveis mais elevados de sobrecarga ${ }^{9,19,50}$, um estudo encontrou uma correlação significativa entre os maiores índices de sobrecarga e o ensino superior ${ }^{50}$, um com cuidadores mais jovens ${ }^{9}$ e outro estudo com cuidadores cônjuges ${ }^{44}$. Nesse estudo realizado por Hwang et al. ${ }^{44}$, os cônjuges cuidadores que também eram mais velhos apresentaram níveis mais elevados de depressão e menor apoio social do que os cuidadores não cônjuges.

Em três estudos o objetivo principal foi a comparação entre populações ${ }^{31,34,50}$. No estudo realizado por Salmon et al. ${ }^{50}$, verificou-se que os cuidadores ativos (familiares que estavam no momento do estudo cuidando de um familiar doente) relataram níveis mais elevados de sobrecarga, maior capacidade de atribuir um significado à experiência de cuidar, pior saúde e menos apoio de outras pessoas do que os cuidadores enlutados. Brazil et al. ${ }^{31}$ não encontraram diferenças em relação a sobrecarga no cuidar, quando comparam cuidadores rurais e urbanos e ambos os grupos relataram baixos níveis de sobrecarga; e Castillo et al. ${ }^{34}$ também não encontraram diferenças entre os cuidadores de pacientes com dor crônica dos cuidadores de pacientes em cuidados paliativos, apesar de que ambos os cuidadores ultrapassaram o ponto de corte para sobrecarga.

Três estudos apresentaram uma associação entre a sobrecarga e o estado de saúde do cuidador, ou seja, os cuidadores com maior nível de sobrecarga apresentavam pior estado de saú- $\mathrm{de}^{30,50,51}$. Wasner et al. ${ }^{51}$ relataram que $33 \%$ dos cuidadores apresentaram elevado risco de doenças psicossomáticas devido à exaustão corporal, distress emocional, dificuldades financeiras e alterações na qualidade de vida do cuidador, que foi fortemente afetada pela sobrecarga no cuidar e pelo estado mental deteriorado do paciente.

Portanto, cuidar de um doente em fim de vida requer muita habilidade para lidar com a situação de doença, a necessidade de prestar cuidados e a sobrecarga. De acordo com o estudo qualitativo desenvolvido por Proot et al. ${ }^{47}$, os cuidadores participantes apontaram a sobrecarga no cuidar, a restrição de atividades, o medo, a insegurança, a solidão, a dificuldade em enfrentar a morte e a falta de apoio emocional, prático e de informações como potenciais fatores para aumentar a vulnerabilidade do cuidador, para além de poderem ser fatores de risco para a fadiga e o burnout.

Outros estudos referem que a sobrecarga do cuidador também pode estar associada a determinadas características dos doentes. Caqueo-Urízar et al. ${ }^{33}$ relatam que os cuidadores de pacientes em estado mais avançado da doença apresentam sobrecarga nas áreas física, social, psíquica e econômica. Grunfeld et al..$^{36}$ encontraram que a depressão e a sobrecarga percebida pelos cuidadores aumentaram com o declínio do estado funcional dos pacientes. Em outro estudo, o aumento da sobrecarga foi associado ao aumento do distress psicológico e da dor do paciente ${ }^{18}$, e dois artigos relataram que os cuidadores de pacientes que necessitavam de mais assistência nas atividades de vida diárias apresentavam maior risco de elevada sobrecarga ${ }^{30,50}$. De acordo com Hwang et al. ${ }^{44}$, os cuidadores com maior percepção de necessidades não satisfeitas do paciente e com maiores níveis de depressão apresentavam maior sobrecarga, e os cuidadores que desejavam mais comunicação por parte dos profissionais de saúde tiveram escores significativamente mais elevados de sobrecarga no cuidar, do que os cuidadores que não necessitavam de tanta comunicação ${ }^{42}$. E Buss et al. ${ }^{32}$ encontraram uma associação estatisticamente significativa entre a percepção de delírio nos pacientes por parte dos cuidadores e a sua sobrecarga. Além dessas variáveis do paciente que influenciam a sobrecarga dos cuidadores, há também um estudo que revela que a sobrecarga do cuidador pode influenciar a qualidade de vida do paciente ${ }^{49}$.

$\mathrm{O}$ distress emocional aparece associado à sobrecarga em dois estudos ${ }^{35,40}$, o transtorno mental comum em um trabalho ${ }^{37}$, a ansiedade em 
três publicações ${ }^{32,34,36}$ e a depressão está associada à sobrecarga em seis artigos ${ }^{28,29,34,36,43,44}$. Porém, $\mathrm{O}$ estudo realizado por Ling et al..$^{38}$ encontrou que os cuidadores enlutados que apresentaram maior nível de sobrecarga no cuidar durante o fim de vida do seu familiar apresentavam no período de luto menor nível de depressão.

Cinco dos artigos selecionados eram longitudinais e avaliaram os cuidadores desde o período de doença do seu familiar até o luto ${ }^{19,28,37-39}$, e um desses estudos encontrou que a sobrecarga foi o fator de maior previsão de satisfação com o cuidado geral, tanto para os pacientes quanto para os cuidadores, ou seja, os pacientes e cuidadores mais satisfeitos com os cuidados prestados apresentavam menor sobrecarga, e o bom funcionamento familiar também influenciou na satisfação com o cuidado em geral ${ }^{39}$. Relacionando a sobrecarga com o luto, Ferrario et al. ${ }^{19}$ encontrou que os cuidadores que apresentavam maiores níveis de sobrecarrega apresentavam menor satisfação com a vida e estavam em maior risco de desajustamento no luto a longo prazo. Kapari et al. ${ }^{37}$ referem que os cuidadores que perceberam a sua experiência de cuidar como sendo de maior sobrecarga apresentaram mais sintomas de transtorno mental comum (TMC) na fase do cuidar, e esses cuidadores com mais sintomas de TMC eram mais suscetíveis de desenvolver um luto complicado. Já Beery et al. ${ }^{28}$ relatam no seu estudo que o nível de sobrecarga no cuidar foi significativamente associado com o nível de depressão e de luto traumático dos cuidadores. Outro artigo que correlaciona a sobrecarga e o luto, foi o estudo transversal realizado por Lai et al. ${ }^{46}$, que demonstrou que a sobrecarga elevada aumenta a possibilidade de luto prolongado. Esse estudo relata ainda que os cuidadores em situação de risco de luto prolongado apresentaram níveis mais elevados de comprometimento em reconhecer sentimentos, ansiedade, depressão e estresse do cuidador do que aqueles cuidadores sem nenhum risco.

Porém, alguns estudos também referem fatores que podem estar associados a um menor nível de sobrecarga nos cuidadores. Salmon et al. ${ }^{50}$ verificaram que um menor nível de sobrecarga foi associado à recepção de apoio de outras pessoas, capacidade dos cuidadores de atribuir um significado a experiência de cuidar e se sentir confortável com as tarefas de cuidar, portanto, os cuidadores que estavam mais confortáveis com a prestação de cuidados apresentaram menor sobrecarga e maior ganho associado à prestação de cuidados. Kim, et al. ${ }^{45}$ referem que $69,1 \%$ dos cuidadores demonstraram uma atitude de esperança, e essa atitude de esperança estava correlacionada com o seu estado psicológico (menos sintomas depressivos), estratégia de coping ativo, menor sobrecarga e maior religiosidade. Kang et al. $^{23}$ encontraram que os cuidadores avaliados já no período de luto relataram altos níveis de ganhos e sobrecarga percebida durante a fase de prestação de cuidados, e que a depressão ou a sobrecarga nos cuidadores não afetaram as consequências positivas da prestação de cuidados ao familiar doente.

\section{Discussão}

É possível verificar no Quadro 1, que a sobrecarga do cuidador não era o principal objetivo na maioria dos artigos. A sobrecarga constituía apenas uma das variáveis avaliadas nos estudos, mas mesmo assim foi possível identificar as consequências da sobrecarga nos cuidadores familiares de pacientes oncológicos e/ ou em cuidados paliativos.

Apesar de a maioria dos artigos terem sido publicados na América do Norte, e na língua inglesa, há também artigos publicados sobre o tema na Europa, Ásia e América do Sul, o que demonstra uma preocupação mundial e relativamente recente com a sobrecarga no cuidar, já que a maior concentração de artigos publicados sobre o tema foi no ano de 2013.

Como na maior parte dos estudos que envolvem cuidadores, a maioria e os principais cuidadores foram as mulheres e os cônjuges. As amostras variaram consideravelmente em tamanho assim como os instrumentos utilizados para avaliar a sobrecarga do cuidador - nessa revisão foram identificados treze instrumentos diferentes -, o que muitas vezes dificulta uma comparação entre os estudos e a generalização dos resultados.

Em relação às características sociodemográficas, a maioria dos estudos não apresenta dados de correlação com a sobrecarga, os poucos dados referentes associam a sobrecarga do cuidar com o sexo feminino ${ }^{9,19,50}$, cônjuges $^{44}$, cuidadores mais jovens ${ }^{9}$ e ao ensino superior ${ }^{50}$, o que não nos permite generalizar os resultados.

Dos artigos selecionados, a maioria encontrou que os cuidadores familiares estão sobrecarregados. Em alguns estudos, a sobrecarga no cuidar aparece associada a determinadas características do paciente como: o estádio avançado da doença $^{41}$, o declínio do estado e capacidade funcional ${ }^{36}$, pacientes que necessitam de mais assistência com 
as atividades de vida diárias ${ }^{30,50}$ aumento do distress psicológico e da dor dos pacientes. Essa associação pode ser explicada devido a dificuldade em gerir os cuidados ao paciente, a sua vida doméstica e particular ${ }^{2,5}$ e, também, devido ao papel mais ativo que assumem nesta fase da doença, uma vez que os pacientes perdem autonomia ${ }^{41}$. Devido à situação de doença do familiar, as demandas de cuidado ao paciente têm prioridade sobre os demais relacionamentos, atividades ocupacionais e de lazer do cuidador. O cuidador quase não tem tempo para si, para atividades sociais, muitas vezes necessita reduzir a carga horária ou até mesmo deixar de trabalhar para cuidar do seu familiar, e, com o excesso de tarefas a serem desempenhadas, decorrentes também da deterioração da saúde do paciente, o cuidador fica sobrecarregado e é muito provável que a sua saúde também fique prejudicada, o que vai ao encontro dos resultados do estudo de Wasner et al. ${ }^{51}$.

Outro estudo ${ }^{42}$ identificou que os cuidadores sobrecarregados desejavam mais comunicação por parte dos profissionais de saúde, e essa questão pode ser explicada devido à necessidade que alguns cuidadores têm de uma explicação mais completa dos sintomas e da condição do paciente para reduzir o seu estresse e ansiedade ${ }^{5}$. De acordo com Sutherland ${ }^{52}$ os familiares que assumiram a responsabilidade de cuidar dos seus cônjuges viam essa atividade como parte do seu papel no relacionamento e como uma expressão de amor. Esses cuidadores assumiram sobrecargas emocionais e físicas adicionais para que os seus cônjuges pudessem ter uma morte pacífica e digna.

Alguns estudos ${ }^{30,50,51}$ encontraram uma correlação positiva entre o pior estado de saúde do cuidador e maior nível de sobrecarga, o que vai de encontro com o relato dos cuidadores no estudo de Castillo et al. ${ }^{34}$, em que um em cada cinco cuidadores identificou problemas de saúde ou problemas físicos como fatores que influenciaram na percepção de sobrecarga. Também sobre a qualidade de vida, o estudo de Williams et al..$^{53}$ corrobora os resultados encontrados por Tang et al. $^{49}$ de que a sobrecarga do cuidador pode influenciar a qualidade de vida do doente, e afirmam que é possível que os cuidadores em distress tenham uma influência negativa sobre o bem-estar do paciente ${ }^{53}$.

Para além das repercussões da sobrecarga na qualidade de vida e na saúde física dos cuidadores, muitos estudos apresentaram evidências da influência da sobrecarga na saúde mental desta população. Ao longo desta revisão fomos consta- tando que a sobrecarga está também relacionada com uma maior sintomatologia psicopatológica - ansiedade $32,34,36$, depressão $\mathrm{o}^{28,29,32,34,36,43}$, distress emocional $^{35,40}$ e transtorno mental comum ${ }^{37}$. Estudos confirmam que a maioria dos cuidadores primários estão clinicamente deprimidos e fazem uso de medicação para depressão, ansiedade e insônia duas ou três vezes mais do que o resto da população ${ }^{34}$. Verificamos também que os cuidadores já apresentavam níveis substanciais de ansiedade e depressão no início do acompanhamento do paciente em cuidados paliativos e que o distress psicossocial ${ }^{35}$, a depressão e a sobrecarga do cuidador aumentaram com o declínio funcional do paciente e com a fase terminal da doença ${ }^{36}$.

O luto também foi correlacionado com a sobrecarga em alguns artigos. Foi possível identificar nesses estudos que os cuidadores que apresentavam maior nível de sobrecarga durante a fase de prestação de cuidados ao paciente estavam mais propensos a desenvolver um luto complicado, prolongado ou traumático ${ }^{19,28,37,46}$. De acordo com a literatura, a sobrecarga no cuidar é um dos fatores de risco para o desenvolvimento de complicações no luto ${ }^{19,21}$. Pesquisas anteriores mostraram que o apoio psicológico prestado aos cuidadores ajuda-os a alcançar resultados de luto mais favoráveis, com risco reduzido de luto complicado $^{54}$, e, de acordo com o estudo de Kang et al. ${ }^{23}$, receber acompanhamento no luto por profissionais de cuidados paliativos foi significativamente associado com os resultados positivos dos ganhos percebidos.

É ainda importante destacar as variáveis que apareceram associadas a menores níveis de sobrecarga, entre elas, a esperança ${ }^{45}$, o apoio social, a capacidade do cuidador de atribuir um significado à experiência de cuidar e se sentir confortável com as tarefas de cuidar ${ }^{50}$. Koop e Strang ${ }^{24}$, no trabalho realizado com cuidadores enlutados, identificaram que os aspectos positivos do papel do cuidador podem superar os aspectos negativos da prestação de cuidados, e Proot et al. ${ }^{47}$ encontraram que continuar com as atividades anteriores, a esperança, manter o controle, a satisfação e um bom suporte social são fatores que podem diminuir a vulnerabilidade do cuidador e proteger contra a fadiga e o burnout.

\section{Conclusão}

O presente estudo pretendeu realizar um levantamento das publicações existentes sobre a so- 
brecarga no cuidar, os fatores relacionados e suas consequências nos cuidadores familiares de pacientes com câncer avançado, em fim de vida e/ ou em cuidados paliativos.

Através da revisão de literatura foi possível compilar os estudos publicados sobre o tema, realizar um levantamento dos instrumentos utilizados para avaliar a sobrecarga do cuidador e resumir os resultados dos artigos. Foi possível constatar que os familiares que assumem o papel de cuidador de pacientes com doença avançada apresentam um maior risco de sobrecarga e morbidade física e mental.

Foram identificados vários fatores que podem influenciar a sobrecarga destes cuidadores, inerentes aos próprios cuidadores ou ao estado funcional e cuidados exigidos pelo paciente, demonstrando a importância de desenvolver meios de suporte e apoio tanto aos pacientes como aos cuidadores. Assim, os profissionais de saúde devem estar cientes das características que estão associadas a níveis mais elevados de sobrecarga no cuidador (sexo feminino, ser cônjuge do paciente, estado de saúde, ansiedade e depressão), para que estejam mais atentos às necessidades dos cuidadores com essas características e possam fornecer um apoio mais específico a nível instrumental e/ ou psicológico, tanto para o paciente como para a família, a fim de reduzir a sobrecarga do cuidador. Este tipo de intervenção poderá também prevenir o desenvolvimento de complicações na fase de luto.

Também é de interesse acadêmico levantar os fatores específicos e importantes relacionados com a sobrecarga do cuidar, harmonizar os instrumentos utilizados para a avaliação da sobrecarga, assim como a recolha dos dados, para que seja possível uma posterior comparação dos resultados dos estudos e generalização dos mesmos. Como são poucos os estudos longitudinais, seria ainda importante ampliar esses trabalhos para podermos compreender melhor as consequências da sobrecarga no cuidador tanto em situações de doença prolongada quando no luto.

\section{Limitações}

Os artigos selecionados para compor a amostra foram apenas textos em inglês, português ou espanhol, publicados em periódicos científicos, enquanto as bases de dados de busca eletrônicas limitaram-se a EBSCO, Web of Knowledge e Bireme, excluindo-se assim, teses de mestrado, doutorado e apresentações de congressos.

Coloca-se, ainda, como potencial viés no processo de revisão: a) o fato da triagem inicial dos resumos e a aplicação dos critérios de inclusão / exclusão para selecionar os 62 estudos potencialmente elegíveis ter sido realizado apenas pela primeira autora; e b) também o fato de não ter sido possível ter acesso ao texto completo de sete dos artigos selecionados na primeira avaliação.

A restrição da população aos cuidadores familiares de pacientes com câncer avançado, em fim de vida e/ ou em cuidados paliativos também pode ser considerado um fator limitador ao número de estudos encontrados sobre a sobrecarga do cuidador.

\section{Colaboradores}

M Delalibera foi responsável pela concepção do artigo, pesquisa, seleção, avaliação dos artigos, interpretação dos dados e redação do texto. J Presa foi responsável pela pesquisa e seleção dos artigos e colaborou na redação do texto. A Barbosa e I Leal foram responsáveis pela revisão crítica do texto.

\section{Agradecimentos}

À Coordenação de Aperfeiçoamento de Pessoa de Nível Superior (CAPES) uma vez que, este trabalho foi desenvolvido no âmbito do doutorado no exterior da autora principal, como bolsista CAPES. 


\section{Referências}

1. Weitzner MA, McMillan SC, Jacobsen PB. Family caregiver quality of life: differences between curative and palliative cancer treatment settings. J Pain Symptom Manage 1999; 17(6):418-428.

2. Given BA, Given CW, Kozachik S. Family support in advanced cancer. CA Cancer J Clin 2001; 51(4):213231.

3. Glajchen $\mathrm{M}$. The emerging role and needs of family caregivers in cancer care. J Support Oncol 2004; 2(2):145-155.

4. Mangan, PA, Taylor, KL, Yabroff, KR, Fleming, DA, Ingham J. Caregiving near the end of life: Unmet needs and potential solutions. Palliat Support Care 2003; 1(3):247-259.

5. Ishii Y, Miyashita M, Sato K, Ozawa T. A family's difficulties in caring for a cancer patient at the end of life at home in Japan. J Pain Symptom Manage 2012; 44(4):552-562.

6. Queiroz AHAB, Pontes RJS, Souza AMA, Rodrigues TB. Percepção de familiares e profissionais de saúde sobre os cuidados no final da vida no âmbito da atenção primária à saúde. Cien Saude Colet 2013; 18(9):26152623.

7. Given B, Wyatt G, Given C, Sherwood P, Gift A, DeVoss $D$, Rahbar M. Burden and depression among caregivers of patients with cancer at the end of life. Oncol Nurs Forum 2004; 31(6):1105-1117.

8. Grov EK, Dahl AA, Moum T, Fosså SD. Anxiety, depression, and quality of life in caregivers of patients with cancer in late palliative phase. Ann Oncol 2005; 16(7):1185-1191.

9. Payne S, Smith P, Dean S. Identifying the concerns of informal carers in palliative care. Palliat Med 1999; 13(1):37-44.

10. Carter P. Family caregivers' sleep loss and depression over time. Cancer Nurs 2003; 26(4):253-259.

11. Grov EK, Dahl AA, Fosså SD, Wahl AK, Moum T. Global quality of life in primary caregivers of patients with cancer in palliative phase staying at home. Support Care Cancer 2006; 14(9):943-951.

12. Juarez GP, Ferrell BP, Uman GP, Podnos YWL. Distress and quality of life concerns of family caregivers of patients undergoing palliative surgery. Cancer Nurs 2008; 31(1):2-10.

13. Milberg A, Strang P, Jakobsson M. Next of kin's experience of powerlessness and helplessness in palliative home care. Support Care Cancer 2004; 12(2):120-128.

14. Nijboer C, Triemstra M, Tempelaar R, Mulder M, Sanderman R, van den BG. Patterns of Caregiver Experiences Among Partners of Cancer Patients. Gerontologist 2000; 40(6):738-746.

15. Goldstein NE, Concato J, Fried TR, Kasl SV, Johnson-Hurzeler RBE. Factors associated with caregiver burden among caregivers of terminally ill patients with cancer. J Palliat Care 2004; 20(1):38-43.

16. Sales E. Family burden and quality of life. Qual Life Res 2003; 12(Supl. 1):33-41.

17. Song JI, Shin DW, Choi JY, Kang J, Baek YJ, Mo HN, Seo MJ, Hwang YH, Lim YK, Lee OK. Quality of life and mental health in the bereaved family members of patients with terminal cancer. Psychooncology 2012; 21(11):1158-1166.
18. Harding R, Higginson IJ, Donaldson N. The relationship between patient characteristics and carer psychological status in home palliative cancer care. Support Care Cancer 2003; 11(10):638-643.

19. Ferrario SR, Cardillo V, Vicario F, Balzarini E, Zotti AM. Advanced cancer at home: caregiving and bereavement. Palliat Med 2004; 18(2):129-136.

20. Robinson-Whelen S, Tada Y, MacCallum RC, McGuire L, Kiecolt-Glaser JK. Long-term caregiving: what happens when it ends? J Abnorm Psychol 2001; 110(4):573584 .

21. Neimeyer, RA, Burke LA. Complicated grief and the end-of-life: Risk factors and treatment considerations. In: Neimeyer RA, Burke LA, editors. Counseling clients near the end-of-life. New York: Springer; 2012. p. 205228.

22. Nijboer C, Tempelaar R, Triemstra M, van den Bos GA, Sanderman R. The role of social and psychologic resources in caregiving of cancer patients. Cancer 2001; 91(5):1029-1039.

23. Kang J, Shin DW, Choi JE, Sanjo M, Yoon SJ, Kim HK, Oh MS, Kwen HS, Choi HY, Yoon WH. Factors associated with positive consequences of serving as a family caregiver for a terminal cancer patient. Psychooncology 2013; 22(3):564-571.

24. Koop PM, Strang SV. The bereavement experience following home-based family caregiving for persons with advanced cancer. Clin Nurs Res 2003; 12(2):127-144.

25. Hudson P. Positive aspects and challenges associated with caring for a dying relative at home. Int J Palliat Nurs 2004; 10(2):58-65.

26. Wong WK, Ussher JPJ. Strength through adversity: bereaved cancer carers' accounts of rewards and personal growth from caring. Palliat Support Care 2009; 7(2):187-196.

27. Thombre A, Sherman AC, Simonton S. Religious coping and posttraumatic growth among family caregivers of cancer patients in India. J Psychosoc Oncol 2010; 28(2):173-188.

28. Beery LC, Prigerson HG, Bierhals AJ, Santucci LM, Newsom JT, Maciejewski PK, Rapp SR, Fasiczka A, Reynolds, C. F. Traumatic Grief, Depression and Caregiving in Elderly Spouses of the Terminally Ill. OMEGA-Journal of Death and Dying 1997; 35(3):261-279.

29. Braun M, Mikulincer M, Rydall A, Walsh A, Rodin G. Hidden morbidity in cancer: spouse caregivers. J Clin Oncol 2007; 25(30):4829-4834.

30. Brazil K, Bédard M, Willison K, Hode M. Caregiving and its impact on families of the terminally ill. Aging Ment Health 2003; 7(5):376-382.

31. Brazil K, Kaasalainen S, Williams A, Rodriguez C. Comparing the experiences of rural and urban family caregivers of the terminally ill. Rural Remote Health 2013; 13(1):1-9.

32. Buss MK, Vanderwerker LC, Inouye SK, Zhang B, Block $\mathrm{SD}$, Prigerson HG. Associations between caregiver-perceived delirium in patients with cancer and generalized anxiety in their caregivers. J Palliat Med 2007; 10(5):1083-1092. 
33. Caqueo-Urízar A, Segovia-Lagos P, Urrutia-Urrutia U, Castillo CM, Lechuga EN. Impacto de la relación de ayuda de cuidadores primarios en la calidad de vida de pacientes con cáncer avanzado. Psicooncología 2013; 10(1):95-108.

34. Castillo OIA, Morales-Vigil T, Vázquez-Pineda F, Sánchez-Román S, Ramos-del Río B, Guevara-López U. Sobrecarga, ansiedad y depresión en cuidadores primarios de pacientes con dolor crónico y terminales. Rev Med Inst Mex Seguro Soc 2008; 46(5):485-495.

35. Dumont S, Turgeon J, Allard P, Gagnon P, Charbonneau C, Vézina L. Caring for a loved one with advanced cancer: determinants of psychological distress in family caregivers. J Palliat Med 2006; 9(4):912-921.

36. Grunfeld E, Coyle D, Whelan T, Clinch J, Reyno L, Earle CC,Willian A, Viola R, Coristine M, Janz T, Glossop, R. Family caregiver burden: results of a longitudinal study of breast cancer patients and their principal caregivers. Can Med Assoc J 2004; 170(12):1795-1801.

37. Kapari M, Addington-Hall J, Hotopf M. Risk factors for common mental disorder in caregiving and bereavement. J Pain Symptom Manage 2010; 40(6):844-856.

38. Ling SF, Chen ML, Li CY, Chang WC, Shen WC, Tang ST. Trajectory and influencing factors of depressive symptoms in family caregivers before and after the death of terminally ill patients with cancer. Oncol Nurs Forum 2013; 40(1):E32-40.

39. Chang YJ, Kwon YC, Lee WJ, Do YR, Seok LK, Kim HT, Park SR, Hong YS, Chung IJ, Yun YH. Burdens, needs and satisfaction of terminal cancer patients and their caregivers. Asian Pac J Cancer Prev 2013; 14(1):209-216.

40. Costa-Requena G, Cristófol R, Cañete J. Caregivers' morbidity in palliative care unit: predicting by gender, age, burden and self-esteem. Support Care Cancer 2012; 20(7):1465-1470.

41. Fleming DA, Sheppard VB, Mangan PA, Taylor KL, Tallarico M, Adams I, Ingham J. Caregiving at the end of life: Perceptions of health care quality and quality of life among patients and caregivers. J Pain Symptom Manage 2006; 31(5):407-420.

42. Fried TR, Bradley EH, O’Leary JR, Byers AL. Unmet desire for caregiver-patient communication and increased caregiver burden. J Am Geriatr Soc 2005; 53(1):59-65.

43. Grov EK, Fosså SD, Sørebø O, Dahl AA. Primary caregivers of cancer patients in the palliative phase: a path analysis of variables influencing their burden. $\mathrm{Soc} S \mathrm{Si}$ Med 2006; 63(9):2429-2439.

44. Hwang SS, Chang VT, Alejandro Y, Osenenko P, Davis C, Cogswell J, Srinivas S, Kasimis B. Caregiver unmet needs, burden, and satisfaction in symptomatic advanced cancer patients at a Veterans Affairs (VA) medical center. Palliat Support Care 2003; 1(4):319-329.

45. Kim SY, Kim JM, Kim SW, Kang HJ, Shin IS, Shim HJ, Cho SH, Chung IJ, Yoon JS. Determinants of a hopeful attitude among family caregivers in a palliative care setting. Gen Hosp Psychiatry 2014; 36(2):165-171.

46. Lai C, Luciani M, Morelli E, Galli F, Cappelluti R, Penco I, Aceto P, Lombardo L. Predictive role of different dimensions of burden for risk of complicated grief in caregivers of terminally ill patients. Am J Hosp Palliat Care 2014; 31(2):189-193.
47. Proot IM, Abu-Saad HH, Crebolder HFJM, Goldsteen M, Luker K A, Widdershoven GAM. Vulnerability of family caregivers in terminal palliative care at home; balancing between burden and capacity. Scand J Caring Sci 2003; 17(2):113-121.

48. Kim SH. The influence of finding meaning and worldview of accepting death on anger among bereaved older spouses. Aging Ment Health 2009;13(1):38-45.

49. Tang ST, Liu TW, Tsai CM, Wang CH, Chang GC, Liu LN. Patient awareness of prognosis, patient-family caregiver congruence on the preferred place of death, and caregiving burden of families contribute to the quality of life for terminally ill cancer patients in Taiwan. Psychooncology 2008; 17(12):1202-1209.

50. Salmon JR, Kwak J, Acquaviva KD, Brandt K, Egan KA. Transformative aspects of caregiving at life's end. J Pain Symptom Manage 2005; 29(2):121-129.

51. Wasner M, Paal P, Borasio GD. Psychosocial care for the caregivers of primary malignant brain tumor patients. J Soc Work End Life Palliat Care 2013; 9(1):74-95.

52. Sutherland $\mathrm{N}$. The meaning of being in transition to end-of-life care for female partners of spouses with cancer. Palliat Support Care 2009; 7(4):423-433.

53. Williams AL, McCorkle R. Cancer family caregivers during the palliative, hospice, and bereavement phases: a review of the descriptive psychosocial literature. Palliat Support Care 2011; 9(3):315-325.

54. Wiese CHR, Morgenthal HC, Bartels UE, Vossen-Wellmann A, Graf BM, Hanekop GG. Post-mortal bereavement of family caregivers in Germany: a prospective interview-based investigation. Wien Klin Wochenschr 2010; 122(13-14):384-389.

Artigo apresentado em 09/07/2014

Aprovado em 02/10/2014

Versão final apresentada em 04/10/2014 